\section{Mosaic analyses using marked activation and deletion clones dissect Arabidopsis SCARECROW action in asymmetric cell division}

\author{
Renze Heidstra, ${ }^{1}$ David Welch, and Ben Scheres \\ Department of Molecular Cell Biology, Utrecht University, \\ $3584 \mathrm{CH}$ Utrecht, The Netherlands
}

In the Arabidopsis root meristem, ground tissue stem cell daughters perform an asymmetric division to form endodermis and cortex. The putative transcription factors SCARECROW (SCR) and SHORTROOT (SHR) regulate this radial patterning event, and the mixed cell fate in scr mutants suggests an atypical role of the SCR gene in asymmetric cell division. Here we use a newly developed site-specific gene activation/deletion system in which induced clones are positively marked with green fluorescent protein (GFP). Using this system, we show that $S C R$ acts cell-autonomously to control asymmetric cell division within the ground tissue. We provide evidence that $S C R$ gene expression is under autoregulatory control, that SCR limits SHR movement, and that transient $S C R$ action is sufficient to separate endodermis and cortex fates by asymmetric cell division.

Supplemental material is available at http://www.genesdev.org.

Received April 13, 2004; revised version accepted June 17, 2004.

Asymmetric cell divisions generate daughter cells with different fates that can be specified by intrinsic fate determinants differentially separated over daughter cells, by extrinsic cues, or by a combination of both (Horvitz and Herskowitz 1992; Scheres and Benfey 1999). In the Arabidopsis root meristem, ground tissue stem cells flank the quiescent center (QC), which functions as a stem cell organizer, and endodermis and cortex are formed through a periclinal division of stem cell daughters (Fig. 1a; Dolan et al. 1993). This asymmetric division requires the putative transcription factors SCARECROW (SCR) and SHORTROOT (SHR). shr mutants form a single ground tissue layer without endodermis characteristics (Benfey et al. 1993). SHR is transcribed in stele cells, but SHR:GFP fusions and immunohistochemistry revealed that the protein resides in the stele and in the adjacent endodermis, ground tissue stem cells, and QC (Helariutta et al. 2000; Nakajima et al. 2001). The loss of endodermal fate in shr mutants makes SHR

[Keywords: Asymmetric cell division; CRE/lox; meristem; pattern formation]

${ }^{1}$ Corresponding author.

E-MAIL r.heidstra@bio.uu.nl; FAX 31-30-2532837.

Article and publication are at http://www.genesdev.org/cgi/doi/10.1101/ gad.305504. a candidate cell fate determinant, but SHR protein is transiently detected in both daughter cells after asymmetric cell division and thus is not an intrinsically segregated determinant.

scr mutants form a single ground tissue layer that expresses both cortical and endodermal markers. SCR is expressed in the endodermis, the ground tissue stem cells, and the QC (Scheres et al. 1995; Di Laurenzio et al. 1996), and SHR is required for up-regulation of SCR expression in the ground tissue (Helariutta et al. 2000). The mixed fate of ground tissue cells in scr suggests that it does not encode a fate determinant but that it controls asymmetric cell division. Mutant analysis has not determined whether SCR is involved in asymmetric fate separation (Fig. 1b, 3), endodermis specification (Fig. 1b, 1), or rotation to a periclinal division plane per se, which could be sufficient for postdivision asymmetry mediated by extrinsic factors (Fig. 1b, 2). One candidate extrinsic factor is the stele-derived SHR protein, whereas no genetic evidence exists to date for cortex determinants. Additional extrinsic factors influencing the asymmetric cell division may exist. First, when ground tissue stem cells that normally give rise to cortex and endodermis are isolated from more mature daughters by laser ablation, their daughters do not perform their characteristic periclinal division (van den Berg et al. 1995). More mature ground tissue cells may thus reinforce periclinal cell division, and SCR may provide such a "top-down" signal because $S C R$ expression persists in the maturing endodermis (Fig. 1c, 1). Second, the QC is a source of non-cell-autonomous signals, which prevent progression of stem cell differentiation, hence excluding periclinal division in the stem cell (Fig. 1c, 2; van den Berg et al. 1997; Sabatini et al. 2003). Accumulation of such a signal resulting from the interruption of stem cell-daughter contact may provide an alternative explanation for the absence of periclinal division observed after ablation of mature daughters.

The role of SCR in the asymmetry of the periclinal ground tissue division and endodermis specification can be addressed by analyzing how cells respond shortly after local induction or elimination of SCR expression. Here we study the effects of clonal activation and deletion of the SCR gene. For this purpose, we have developed a CRE/lox-based site-specific recombination system consisting of two vectors, in which recombination events are positively marked with green fluorescent protein (GFP) expression. Our results demonstrate a transient role for SCR in initiating and stabilizing the asymmetry of cell division, as well as a role for $S C R$ in restraining SHR movement, which represents a noncanonical mechanism for asymmetric cell division.

\section{Results and Discussion \\ Clonal activation reveals SCR involvement in division asymmetry}

SCR induces a periclinal division in the daughter of the ground tissue stem cell only, but ectopic expression of SHR results in multiple ground tissue layers indicating that limiting SHR expression is a mechanism to prevent continued activation of $S C R$ and additional periclinal ground tissue divisions. Yet SHR and SCR are present in 


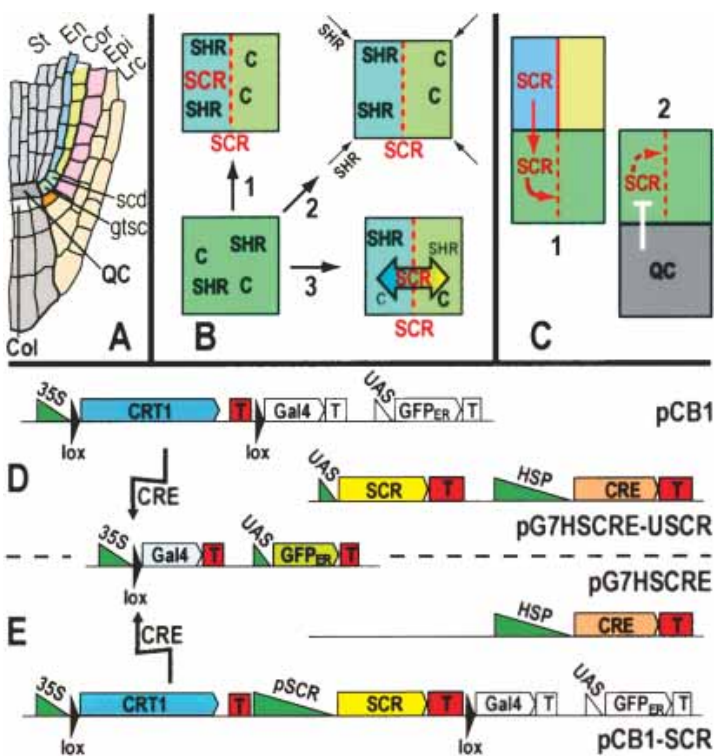

Figure 1. Site-specific $S C R$ gene activation and deletion to investigate alternative possibilities for SCR function in asymmetric division. (a) Schematic representation of cell types present in the Arabidopsis root meristem. Radially organized are the stele $(\mathrm{St})$, endodermis (En), cortex (Cor), epidermis (Epi), and lateral root cap (Lrc). In the proximal-distal plane, quiescent center $(\mathrm{QC})$ and columella (Col). (gtsc) Ground tissue stem cell; (scd) stem cell daughter. (b) Possibilities for SCR function in establishing asymmetry during periclinal ground tissue cell division. SCR is required for the execution of the periclinal division $(1,2,3)$. (1) SCR and SHR are required to maintain endodermis fate; $\mathrm{C}$ determines cortex fate. (2) SCR plays no part in division asymmetry, only external factors determine endodermal and cortex fate. (3) During periclinal division, SCR separates endodermis and cortex fates. (c) Two possible signaling pathways allowing periclinal cell division in the ground tissue stem cell daughters. (1) Mature cells act as a patterning template and reinforce periclinal cell division. (2) QC signaling prevents differentiation and periclinal division in the stem cell. (d) Clonal SCR gene activation in scr-4 using vectors $p C B 1$ and $p G 7 H S C R E-U S C R$. Heat-shock activation of CRE recombinase mediates excision of the sequences between the direct repeat lox recombination sites. The $35 \mathrm{~S}$ constitutive promoter then drives GAL4VP16 expression, resulting in transactivation of $S C R$ expression and $G F P_{E R}$, thereby marking the cells with recombination events. (e) Clonal deletion of SCR using pCB1-SCR complemented scr-4 and pG7HSCRE. Heat-shock activation of CRE recombinase mediates excision of $S C R$, resulting in the 35S-driven GAL4VP16 and transactivation of GFP ${ }_{E R}$ expression, thereby marking the scr-4 mutant cells. Color-filled objects represent active promoters (green), transcribed genes (blue, green, orange, yellow), and terminators (red).

the entire endodermal ground tissue layer (Helariutta et al. 2000; Nakajima et al. 2001). To test whether only certain ground tissue cells are able to perform the periclinal division, we investigated their competence to respond to induced SCR gene expression in the $5 c r-4$ nullmutant background.

We designed a set of two vectors that can be used to generate both activation and deletion clones while positively marking the cells in which recombination has taken place with endoplasmic reticulum (ER)-localized GFP (GFP $\mathrm{GR}_{\mathrm{E}}$ Fig. 1d,e). We combined the CRE/lox recombination system with the GAL4/UAS transactivation system. The $p C B 1$ binary vector contains the recombination cassette consisting of the CRT1 resistance gene flanked by two direct repeat lox recombination sites. This construction separates and prohibits the con- stitutive $35 S$ promoter from inducing GAL4VP16 transcription and transactivating $G F P_{E R}$. The $p G 7 H S C R E$ construct harbors the CRE recombinase driven by Arabidopsis HSP18.2 heat-shock promoter. To study activation clones (Fig. 1d), the SCR gene is placed under control of the $U A S$ promoter (USCR) in the $p G 7 H S C R E$ vector. scr-4 plants harboring a single-copy $C B 1$ insertion were crossed with scr-4,G7HSCRE-USCR plants, and the resulting F1 seedlings were used to generate $\mathrm{GFP}_{\mathrm{ER}^{-}}$ marked gene activation clones upon heat-shock induction, which can be recorded in the living organism.

The earliest time point of $\mathrm{GFP}_{\mathrm{ER}}$ expression, mainly in the columella and root cap tissues, was observed after $\sim 8$ h. Up to $16 \mathrm{~h}$ after heat shock (has), newly induced clones expressing $\mathrm{GFP}_{\mathrm{ER}}$ appeared. $\mathrm{GFP}_{\mathrm{ER}}$-positive $\left(\mathrm{GFP}_{\mathrm{ER}}{ }^{+}\right)$clones were only observed in seedlings subjected to heat-shock induction (data not shown). Activation of SCR expression in all meristematic scr-4 mutant ground tissue cells can induce a periclinal division (Fig. $2 \mathrm{a}-\mathrm{c}, \mathrm{e}, \mathrm{f})$. No effects of $S C R$ activation were detected in other tissues, nor did SCR activation in cells neighboring the mutant ground tissue have any effect (Fig. 2g,h). In addition, heat shock alone did not induce any divisions in the ground tissue in scr-4 plants alone or in $s c r-4$

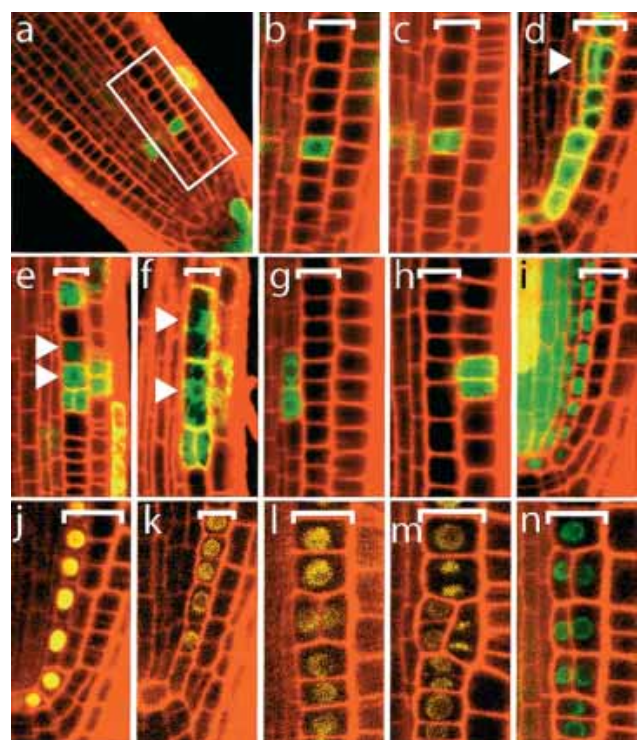

Figure 2. Induction of periclinal cell division by $S C R$ activation clones. (a) Root tip showing $\mathrm{GFP}_{\mathrm{ER}}$-marked clones with SCR expression 16 has. (b) Close-up of section depicted in $a$, showing ground tissue clone. $(c)$ Ground tissue clone from $a$ and $b$ has divided periclinally 24 has. (d) Additional periclinal ground tissue divisions (arrowhead) in $s c r-2$ roots marked by $S C R$ promoter-driven $\mathrm{GFP}_{\mathrm{ER}} \cdot(e)$ $\mathrm{GFP}_{\mathrm{ER}}$-marked $S C R$ activation clone at the border of the meristem shows a periclinally divided ground tissue cell flanked by undivided proximal cells (arrowheads, 16 has). (f) At 24 has, the $\mathrm{GFP}_{\mathrm{ER}}$-marked cells have elongated and not divided again indicating their displacement from the meristem. $(g, h)$ Vascular and epidermal clones do not induce periclinal divisions in the neighboring ground tissue. (i) SHR promoter-driven GFP:SHR expression in wild-type roots. GFP:SHR protein is localized to the nucleus in the endodermis, ground tissue stem cells, and QC. (j) Expression of $p S C R:$ :YFP ${ }_{H 2 B}$ in endodermis, ground tissue stem cells, and QC in a wild-type root. $(k)$ pSCR:: YFP ${ }_{H 2 B}$ is absent from the QC and low in scr-4 mutant ground tissue. $(1, \mathrm{~m})$ pSCR::YFP ${ }_{H 2 B}$ is present in both ground tissue layers after periclinal divisions in $s c r-4$ roots. (n) GFP:SHR is present in both ground tissue layers after periclinal divisions in $s c r-4$ roots. Brackets indicate ground tissue. Internal tissues are to the left. 
plants harboring either construct (data not shown). These results show that in the absence of $S C R$, all ground tissue cells are competent to perform a periclinal division as long as they reside in the meristematic zone, indicating the necessity for an active mechanism to restrict periclinal division to stem cell daughters.

Rare periclinal ground tissue divisions do occur in scr-4 null mutants, and we investigated whether these divisions can be asymmetric in the absence of SCR (Fig. $1 b, 2)$. We introduced the $S C R$ promoter-driven nuclearlocalized Histon2B:YFP ( $\left.p S C R:: Y F P_{H 2 B}\right)$ as a marker for endodermal fate. In the $s c r-4$ mutant, there is a low level of expression from the $S C R$ promoter observed in the mutant ground tissue layer, whereas expression is absent in the QC region compared with wild-type plants (Fig. $2 \mathrm{j}, \mathrm{k})$. All periclinal divisions observed in $s c r-4$ resulted in the equal distribution and maintenance of the pSCR::YFP ${ }_{H 2 B}$ marker over both layers, indicative of a symmetric division (Fig. 21,m). In the weaker scr-2 mutant allele, which shows additional periclinal ground tissue divisions creating up to three cell files, SCR promoter-driven $\mathrm{GFP}_{\mathrm{ER}}$ is also equally distributed, indicating symmetric divisions (Fig. 2d), although expression in the inner ground tissue layer is not always strongly maintained. These results indicate that $S C R$ is required for the asymmetry of the periclinal ground tissue division, but not for the execution of the division per se.

SHR protein can translocate from the stele to the single ground tissue layer in scr mutants, indicating that SHR movement from the stele does not require SCR activity (Helariutta et al. 2000; Wysocka-Diller et al. 2000; Nakajima et al. 2001). However, ectopically expressed SHR:GFP moves from the epidermis to the ground tissue in a $s c r$ mutant background but not in wild type, which suggests a role for SCR in restricting SHR localization (Sena et al. 2004). Indeed, SHR promoter-driven GFP: SHR fusion protein is present at low levels and is maintained in both ground tissue layers on periclinal divisions observed in scr-4 (Fig. 2i,n), demonstrating that symmetric division and SHR movement or perdurance beyond a single cell layer occurs in the absence of functional SCR.

To determine the asymmetry of the induced periclinal ground tissue divisions in activation clones, we again used the $p S C R:: Y F P_{H 2 B}$ marker. The lines were analyzed using two different confocal microscope settings (see Materials and Methods). In the GFP + YFP mode, fluorescence from both GFP and YFP are detected, whereas in the YFP mode, only YFP is detected. After induction of SCR, pSCR::YFP ${ }_{H 2 B}$ is induced in cells marked by clonally activated GFP $\mathrm{ER}_{\mathrm{ER}}$ and is equally divided over the inner and outer cells on periclinal division at 16 has (Fig. $3 \mathrm{a}, \mathrm{b})$. By 40 has, $p S C R:: Y F P_{H 2 B}$ disappears from the outer cell while being strongly maintained in the inner cell (Fig. 3c,d), matching SCR regulation in ground tissue stem cell daughters (Wysocka-Diller et al. 2000).

To address whether SCR could act as an extrinsic signal in the ground tissue (Fig. 1c, 1) we investigated the cell autonomy of SCR activation. About $25 \%$ of the observed ground tissue clones also contained $\mathrm{GFP}_{\mathrm{ER}}{ }^{-}$cells (Fig. 3e,f). Sometimes these ground tissue cells revealed weak, transient $\mathrm{GFP}_{\mathrm{ER}}$ expression. This indicates the formation of G2 clones, in which, after a single excision in the G2 phase of the cell cycle, only one of the two daughter cells receives the recombined chromosome, whereas both cells initially received SCR transcript. Oc-

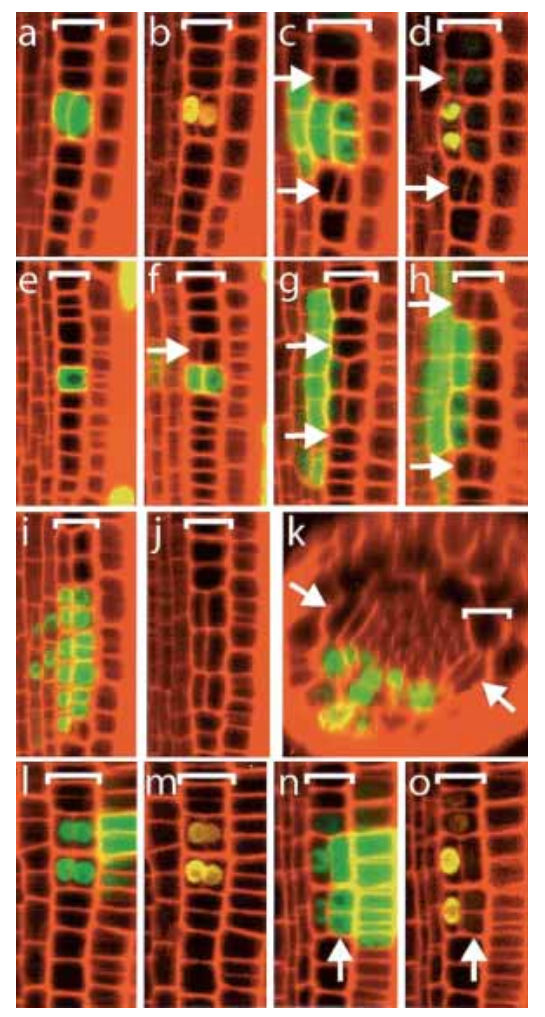

Figure 3. Activation clones reveal cell-autonomous $S C R$ function in asymmetric division. $(a-d) p S C R:: Y F P_{H 2 B}$ is induced in a $S C R$ activation clone and divided over the inner and outer ground tissue cells on periclinal division at 16 has $(a, b)$. Later, $p S C R:: Y F P_{H 2 B}$ separates asymmetrically to the inner cells. Induced periclinal ground tissue divisions observed in cells flanking the clone (arrows) exhibit low levels of $p S C R:: Y F P_{H 2 B}$ that is divided equally over both cells $\left(c, d ; 40\right.$ has). (e,f) $\mathrm{GFP}_{\mathrm{ER}}$-marked ground tissue $S C R$ activation clone $\left(e ; 16\right.$ has) induces periclinal division in a flanking $\mathrm{GFP}_{\mathrm{ER}}{ }^{-}$cell $(f ;$ arrow; 24 has). $(g, h) \mathrm{GFP}_{\mathrm{ER}}{ }^{-}$ground tissue cells flanking a periclinal $\mathrm{GFP}_{\mathrm{ER}}$-marked SCR activation G2-clone ( $g$, arrows, 16 has) are nonautonomously induced to perform periclinal divisions ( $h$; arrows; 24 has). (i-k) Periclinal division in $\mathrm{GFP}_{\mathrm{ER}}{ }^{-}$ground tissue cells flanking a SCR:GFP activation clone in the same (i) and adjacent (j) cell file 40 has. $(k)$ Optical cross-section of the root in $i$ and $j$, revealing two nonautonomously induced periclinal ground tissue divisions in cell files flanking the SCR:GFP activation clone (arrows). Nuclear SCR:GFP strictly colocalizes with the $\mathrm{GFP}_{\mathrm{ER}}$-marked activation clone. $(1-O)$ pSCR ::YFP ${ }_{H 2 B}$ is divided over both ground tissue layers following periclinal division in a $S C R$ activation clone $(1, m ; 16$ has). At 24 has, functional SCR gene expression marked by GFP ER $_{\text {ex- }}$ pression throughout the cells localizes to the outer cells in the periclinal G2-clone ( $n$; arrow), whereas nuclear $p S C R::$ YFP $_{H 2 B}$ still separates asymmetrically to the inner cells $(o) .(a, c, 1, n) \mathrm{GFP}_{\mathrm{ER}}$ and $\mathrm{YFP}_{\mathrm{H} 2 \mathrm{~B}}$ are visualized simultaneously in the GFP mode (see Materials and Methods). Brackets indicate ground tissue. Internal tissues are to the left.

casionally, periclinally divided $\mathrm{GFP}_{\mathrm{ER}}{ }^{-}$cells occurred apically and basally to G2 clones formed by periclinal division, which therefore are clonally unrelated to the activation event and must be nonautonomously induced (Fig. 3g,h). In addition, nonautonomously induced divisions were found in ground tissue files neighboring $\mathrm{GFP}_{\mathrm{ER}}{ }^{+} \mathrm{SCR}$ expressing ground tissue cells (Fig. 3i-k).

To examine whether these apparently nonautonomous divisions were caused by SCR movement, we replaced $S C R$ with a fully functional SCR:GFP fusion gene. SCR:GFP was never observed in nonautonomously induced periclinally divided cells neither before nor fol- 
lowing the observed division, and hence we found no evidence for SCR movement (Fig. 3i-k; data not shown). In nonautonomously induced periclinal cell divisions (induced before 24 has; data not shown), the SCR promoter is not activated, and the low background pSCR:: YFP ${ }_{H 2 B}$ expression is distributed evenly, indicating that these periclinal cell divisions are symmetric (Fig. 3c,d; arrows). Cells may respond by periclinal division because of artificially high expression of SCR from the $35 \mathrm{~S}$ promoter or by movement of the highly expressed GAL4VP16 protein in the activation clones, and therefore a final conclusion on SCR cell autonomy requires the analysis of deletion clones (see below). A similar observation was made in flowers, where $M L 1$-driven high expression of AP1 induced a more extensive rescue of the ap 1 mutant phenotype compared with AP1 clones in mosaic plants, suggesting that higher levels of AP1 in L1 had limited nonautonomous effects (Sessions et al. 2000).

We next examined the dynamics of $p S C R:: Y F P_{H 2 B}$ activity in periclinal G2 clones to determine whether $S C R$ is permanently or transiently required to maintain the asymmetry of the division (Fig. 1b, 1 vs. 3). Heat-shock activation of $S C R$ expression results in $p S C R:: Y F P_{H 2 B}$ induction in ground tissue cells that divide periclinally even before $\mathrm{GFP}_{\mathrm{ER}}$ is detected in the GFP + YFP mode (Fig. 31,m). After the division, SCR expression marked by $\mathrm{GFP}_{\mathrm{ER}}$ fluorescence throughout the cells is separated to the outer cells shown in the GFP + YFP mode (Fig. 3n). The YFP detection mode shows that the nuclear pSCR::YFP ${ }_{H 2 B}$ marker still becomes asymmetrically expressed in inner ground tissue cells that no longer transcribe functional SCR (Fig. 3o).

Our results suggest that ground tissue cells divide asymmetrically only if SCR is present in these cells. Importantly, $S C R$ is only transiently required to promote asymmetry indicating rapid separation of cell fates. Our data show that SCR is not exclusively promoting cell division plane rotation in the ground tissue. Symmetric periclinal divisions observed in $s c r$ mutants show that periclinal division per se is not dependent on SCR presence, but the maintenance of GFP:SHR in both layers suggests that one role of SCR is to restrict SHR to a single tissue layer that prevents additional periclinal cell divisions and specification of endodermal layers as observed in SHR ectopic expression studies (Helariutta et al. 2000; Nakajima et al. 2001; Sena et al. 2004).

\section{Deletion clones reveal cell autonomy of SCR action, feedback regulation, and early fate determination}

To further examine the autonomy of SCR action, we tested SCR deletion clones initiated in the ground tissue stem cell whose surrounding cells have near wild-type levels of $S C R$ expression. For clonal deletion experiments, the $p C B 1$ vector was used to complement the $s c r-4$ mutant by cloning the SCR gene expressed from its own promoter within the recombination cassette $(p C B 1$ $S C R$, Fig. 1e) and selecting transformants with a single copy insert. Subsequent introduction of G7HSCRE by crossing reveals the effects of deleting $S C R$ gene activity in heat-shock-induced GFP $\mathrm{ER}$-marked clones in a phenotypically wild-type plant (Fig. 1e).

Three types of clones were observed, consisting of mutant ground tissue derived from $\mathrm{scr}^{-/-}$stem cells attached to either wild-type endodermis and cortex or one of the two layers being $s \mathrm{cr}^{-/-}$. Optical cross-sections also revealed wild-type ground tissue files flanking the deletion clones. None of these configurations rescued periclinal divisions in daughters of $s c r$ mutant stem cells (Fig. 4a,b,e; data not shown). Thus, deletion of SCR from ground tissue stem cells invariably results in a single layered ground tissue typical for the $s c r$ mutant phenotype, strongly suggesting that SCR at wild-type levels acts strictly cell autonomously in periclinal ground tis-

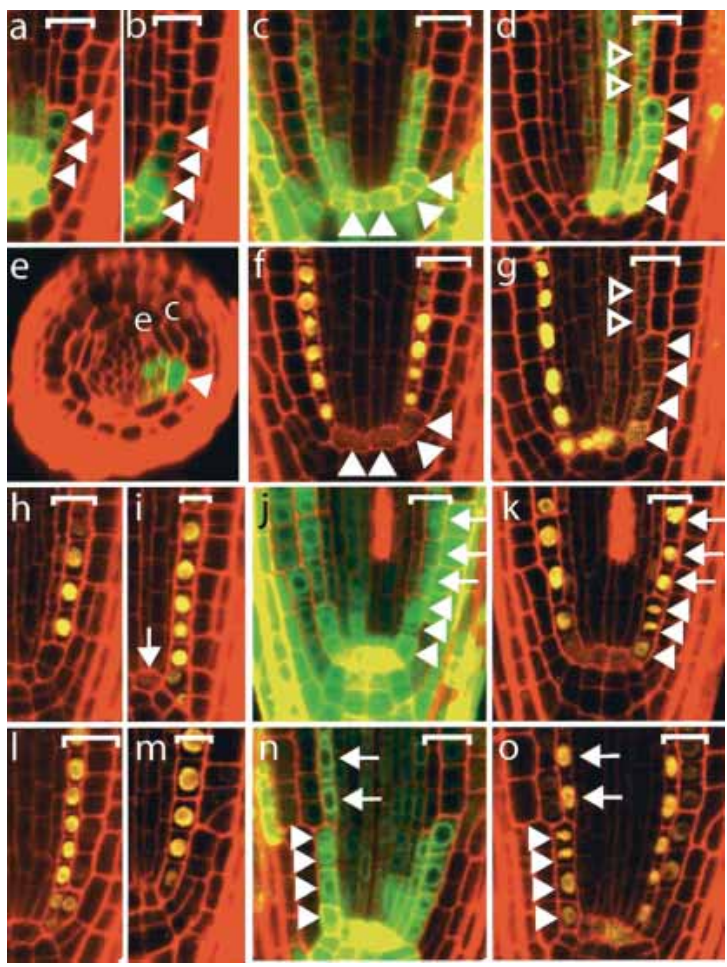

Figure 4. Cell autonomy, autoregulation, and ground tissue determination revealed by $S C R$ deletion clones. $(a, b, e) \mathrm{GFP}_{\mathrm{ER}}$-marked single-layered ground tissue SCR deletion clones (arrowheads) originating from a scr-1- stem cell are not induced to divide periclinally by neighboring cells expressing wild-type SCR levels. (e) Optical cross-section of a root containing a $\mathrm{GFP}_{\mathrm{ER}}$-marked $S C R$ deletion clone circumpherentially flanked by wild-type ground tissue. $(c, f)$ $\mathrm{QC}$, ground tissue stem cells, and their daughters rapidly lose pSCR ::YFP ${ }_{H 2 B}$ when SCR expression is eliminated (arrowheads), whereas $p S C R:: Y F P_{H Р B}$ is maintained in the already formed endodermis 40 has. $(d, g)$ In a different root at 72 has, $p S C R:: Y F P_{H 2 B}$ is reduced to background levels in the already formed endodermis within a SCR deletion clone (open arrowheads). pSCR::YFP ${ }_{H 2 B}$ remains absent in the single ground tissue layer originating from the mutant stem cell (arrowheads). (h) $p C 02:: Y F P_{H 2 B}$ marker expression in the cortex of wild-type roots is excluded from QC, ground tissue stem cells, and their single-layered daughters. (i) pCo2::YFP ${ }_{H 2 B}$ expression in the single-layered ground tissue and QC (arrow) in scr-4 roots. $(j, k)$ Massive $\mathrm{GFP}_{\mathrm{ER}}$ marked the $S C R$ deletion clone, including the ground tissue that contains a pile of single-layered cells (arrowheads, 48 has). $p$ Co2::YFP ${ }_{H 2 B}$ remains present in the cortex and is also present in the single-layered ground tissue ( $k$, arrows). (l) $p E n 7:: Y F P_{H 2 B}$ expression in the endodermis of wild-type roots is only excluded from the QC cells. $(\mathrm{m}) \mathrm{pEn} 7:: \mathrm{YFP}_{\mathrm{H} 2 \mathrm{~B}}$ expression in the single layered ground tissue in $s c r-4$ roots. $(n, 0)$ Massive $\mathrm{GFP}_{\mathrm{ER}}{ }^{-}$ marked SCR deletion clone, including the ground tissue that contains a pile of single layered cells (arrowheads, 48 has). (o) pEn 7:: YFP ${ }_{H 2 B}$ remains present in the endodermis (arrows) and is also present in the single-layered ground tissue. Brackets indicate ground tissue. (e) Endodermis; (c) cortex. $(a, b, h, i, l, m)$ Internal tissues are to the left. 
sue division. Although the cell autonomy eliminates SCR as a possible top-down signal, its ability to induce asymmetric periclinal divisions in meristematic ground tissue cells in the absence of mature endodermis and cortex acting as a patterning template effectively rules out the need for top-down signaling (Fig. 1c, 1) to pattern the ground tissue.

In strong $S C r$ mutants, expression from the SCR promoter is absent from the QC and reduced in the mutant ground tissue (Wysocka-Diller et al. 2000; Sabatini et al. 2003), which may reflect autoregulatory control of SCR transcription or an indirect effect. $S C R$ deletion clones provide a test for the requirement of $S C R$ activity in maintaining its own expression. Upon deletion of $S C R$ expression, $p S C R:: Y F P_{H 2 B}$ in $\mathrm{QC}$ and ground tissue stem cells disappears within 40 has, whereas marker expression in the endodermis remains present (Fig. 4c,f). pSCR:: YFP ${ }_{H 2 B}$ expression remains absent in the single layered ground tissue originating from the mutant stem cells. In time, reduction of $p S C R:: Y F P_{H 2 B}$ expression occurs in the already formed endodermis within the deletion clone, but background levels remain detectable (Fig. $4 \mathrm{~d}, \mathrm{~g})$. However, GFP:SHR is still detected in the QC and ground tissue cells in scr mutants (Nakajima et al. 2000; data not shown), indicating that the $S C R$ promoter is no longer responsive to SHR. Our results indicate that $S C R$ expression in QC and ground tissue stem cells requires its own gene product, whereas in maturing ground tissue cells, the expression is "locked" in a much less responsive state and can be maintained in its absence once the periclinal ground tissue division has occurred. This demonstrates that ground tissue stem cells have intrinsic regulatory circuits different from their daughters.

To examine the effect of $S C R$ deletion on asymmetric fate specification, we studied the expression of the independent endodermis and cortex specific transcripts En7 and Co2. The promoters of both genes were fused to $Y_{H 2 P}$. $p$ CO2:: YFP ${ }_{H 2 B}$ is highly expressed in the cortex but excluded from the QC, the ground tissue stem cells, and their undivided daughters in wild type, whereas it is expressed in the entire single-layered mutant ground tissue and QC in scr-4 roots (Fig. 4h,i). pEn7::YFP ${ }_{H 2 B}$ is highly expressed in the endodermis and is excluded from the QC in wild type, whereas it is expressed in the mutant ground tissue and QC in scr-4 roots (Fig. 4l,m; data not shown). These markers confirm previous data on the mixed identity of the ground tissue layer in scr mutants (Di Laurenzio et al. 1996) and reveal a role for SCR in inhibiting En7 and Co2 expression in QC and QC plus ground tissue stem cells, respectively. Surprisingly, both markers are maintained in their respective ground tissue layer in clones containing cells that underwent asymmetric division before $S C R$ deletion (Fig. 4j,k,n,o, arrows). pCo2:: YFP ${ }_{H 2 B}$ expression is induced in the singlelayered ground tissue originating from the $\mathrm{Scr}^{-1}$ stem cells (Fig. 4j,k).

The endodermis and cortex markers indicate that the SCR-mediated asymmetric cell division leads to immediate and stable separation of cell fates. This is in agreement with the transient requirement of SCR for cell fate separation on periclinal ground tissue division observed in activation clones. In analogy with animal systems, we speculate that such a "locking" mechanism may be caused by chromatin-mediated processes (Orlando 2003; Rasmussen 2003).

Our results support a model in which $S C R$ functions cell autonomously to induce rotation of cell division plane and asymmetry of division in the ground tissue (Fig. 5). One aspect of the model is the strong autoregulatory $S C R$ expression in QC and ground tissue stem cells versus the maintained postdivision expression of $S C R$ in the maturing endodermis. $S C R$ expression is induced by SHR in the QC and elevated in the ground tissue, and thereafter, autoinduction of expression becomes the main source of gene regulation upon which the SCR promoter appears to be desensitized to SHR. $S C R$ in the QC is required to specify QC fate and to maintain the surrounding stem cells. In the ground tissue stem cell daughters, SCR induces the asymmetric periclinal division. The active QC prevents this division in the ground tissue stem cells. Upon periclinal division $S C R$ causes a rapid separation of endodermis and cortex gene expression patterns and locks the cells in their respective fates. SCR and SHR expression in the outer cortex cell is rapidly reduced to ensure a single periclinal ground tissue division. We postulate that during separation of cell fates, additional factors required for the execution of the periclinal division are segregated or degraded from the SHR and SCR expressing endodermal cells, thus preventing repeated periclinal divisions. The function of SCR in the endodermis is to sequester SHR and prevent movement beyond a single cell file, thereby preventing the renewed induction of SCR in the cortex, which would lead to additional asymmetric divisions. This mechanism effectively limits asymmetric division to ground tissue stem cell daughters.

Our data suggest an unconventional mechanism for asymmetric cell division, in which a cell fate determi-

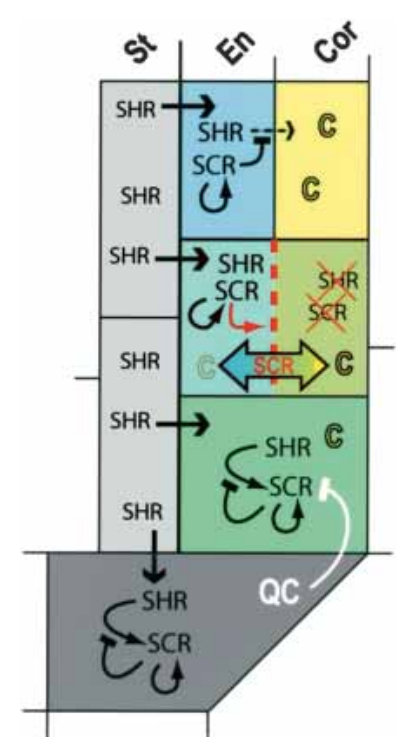

Figure 5. $S C R$ function in $\mathrm{QC}$ and ground tissue. SHR moves from the stele to the QC and ground tissue cells. In the QC and ground tissue stem cells, SCR expression is induced by SHR and maintained by autoregulation. The inductive capacity of SHR is lost on SCR expression. The QC prevents SCR induced periclinal cell division in the ground tissue stem cell. SCR induces the periclinal division in the ground tissue stem cell daughter. SCR mediates rapid endodermal (SHR) and cortical (C) fate separation and segregation of factors required for execution of the periclinal division. Residual SHR and SCR in the outer cell is degraded. In the endodermis, SCR prevents SHR movement to the neighboring cortex cell file, thereby preventing additional periclinal divisions. 
nant that can be extrinsically provided before division (SHR) is actively maintained only in one daughter cell by the downstream effectors of a transcription factor (SCR) that is under its control. SCR effectors must rapidly regulate rotation of cell division plane and segregation of unknown factors that influence both SHR and SCR oppositely in each daughter cell. Regulators of SHR movement and stability, and proteins that can influence positioning of the cell plate and asymmetric segregation of factors, should be among these effectors. Analysis of suppressors and enhancers of the $s c r$ phenotype and molecular approaches to identify SCR target genes should reveal the identity of proteins contributing to the complex control of asymmetric cell division in the ground tissue.

\section{Materials and methods}

Additional details on growth conditions, number of plants and clones analyzed, and cloning strategies are provided in the Supplemental Material.

Heat shock and image analysis of clones

Heat shocks were applied to seedlings grown on vertical plates by incubation at $37^{\circ} \mathrm{C}$ for $18 \mathrm{~min}$ to $1 \mathrm{~h}$, thereby generating increasingly larger clones. Imaging and analysis of clones was performed using a Leica SP2 inverted confocal microscope and the accompanying software. Root cell walls were stained with propidium iodine. In the GFP channel, GFP and YFP are visualized simultaneously by excitation at $488 \mathrm{~nm}$ and by collection at $498-523 \mathrm{~nm}$. In the YFP channel, only YFP is visualized at excitation at $514 \mathrm{~nm}$ and collection at $530-560 \mathrm{~nm}$.

\section{Acknowledgments}

We are indebted to Keiji Nakajima and Philip Benfey for providing mutants and constructs and to the Benfey lab, and in particular Kim Gallagher, for valuable discussions and suggestions.

The publication costs of this article were defrayed in part by payment of page charges. This article must therefore be hereby marked "advertisement" in accordance with 18 USC section 1734 solely to indicate this fact.

\section{References}

Benfey, P.N., Linstead, P.J., Roberts, K., Schiefelbein, J.W., Hauser, M.T., and Aeschbacher, R.A. 1993. Root development in Arabidopsis: Four mutants with dramatically altered root morphogenesis. Development 119: 57-70.

Di Laurenzio, L., Wysockadiller, J., Malamy, J.E., Pysh, L., Helariutta, Y., Freshour, G., Hahn, M.G., Feldmann, K.A., and Benfey, P.N. 1996. The SCARECROW gene regulates an asymmetric cell division that is essential for generating the radial organization of the Arabidopsis root. Cell 86: 423-433.

Dolan, L., Janmaat, K., Willemsen, V., Linstead, P., Poethig, S., Roberts, K., and Scheres, B. 1993. Cellular organization of the Arabidopsis root. Development 119: 71-84.

Helariutta, Y., Fukaki, H., Wysocka-Diller, J., Nakajima, K., Jung, J., Sena, G., Hauser, M.T., and Benfey, P.N. 2000. The SHORT-ROOT gene controls radial patterning of the Arabidopsis root through radial signaling. Cell 101: 555-567.

Horvitz, H.R., and Herskowitz, I. 1992. Mechanisms of asymmetric cell division: Two Bs or not two Bs, that is the question. Cell 68: 237-255.

Nakajima, K., Sena, G., Nawy, T., and Benfey, P.N. 2001. Intercellular movement of the putative transcription factor SHR in root patterning. Nature 413: 307-311.

Orlando, V. 2003. Polycomb, epigenomes, and control of cell identity. Cell 112: 599-606.

Rasmussen, T.P. 2003. Embryonic stem cell differentiation: A chromatin perspective. Reprod. Biol. Endocrinol. 1: 100.

Sabatini, S., Heidstra, R., Wildwater, M., and Scheres, B. 2003. SCARE$C R O W$ is involved in positioning the stem cell niche in the Arabidopsis root meristem. Genes \& Dev. 17: 354-358.
Scheres, B. and Benfey, P.N. 1999. Asymmetric cell division in plants. Annu. Rev. Plant Physiol. Plant Mol. Biol. 50: 505-537.

Scheres, B., Di Laurenzio, L., Willemsen, V., Hauser, M.T., Janmaat, K., Weisbeek, P., and Benfey, P.N. 1995. Mutation affecting the radial organization of the Arabidopsis root display specific defects throughout the embryonic axis. Development 121: 53-62.

Sena, G., Jung, J.W., and Benfey, P.N. 2004. A broad competence to respond to SHORT-ROOT as revealed by tissue-specific ectopic expression. Development 131: 2817-2826.

Sessions, A., Yanofsky, M.F., and Weigel, D. 2000. Cell-cell signaling and movement by the floral transcription factors LEAFY and APETALA1. Science 289: 779-782.

van den Berg, C., Willemsen, V., Hage, W., Weisbeek, P., and Scheres, B. 1995. Cell fate in the Arabidopsis root meristem determined by directional signalling. Nature 378: 62-65.

van den Berg, C., Willemsen, V., Hendriks, G., Weisbeek, P., and Scheres, B. 1997. Short-range control of cell differentiation in the Arabidopsis root meristem. Nature 390: 287-289.

Wysocka-Diller, J.W., Helariutta, Y., Fukaki, H., Malamy, J.E., and Benfey, P.N. 2000. Molecular analysis of SCARECROW function reveals a radial patterning mechanism common to root and shoot. Development 127: 595-603. 


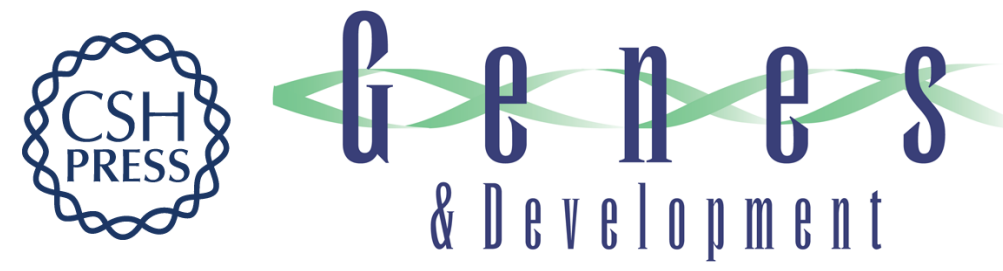

\section{Mosaic analyses using marked activation and deletion clones dissect Arabidopsis SCARECROW action in asymmetric cell division}

Renze Heidstra, David Welch and Ben Scheres

Genes Dev. 2004, 18:

Access the most recent version at doi:10.1101/gad.305504

Supplemental http://genesdev.cshlp.org/content/suppl/2004/08/11/18.16.1964.DC1
Material

References This article cites 16 articles, 7 of which can be accessed free at:

http://genesdev.cshlp.org/content/18/16/1964.full.html\#ref-list-1

License

Email Alerting

Receive free email alerts when new articles cite this article - sign up in the box at the top

Service

right corner of the article or click here.

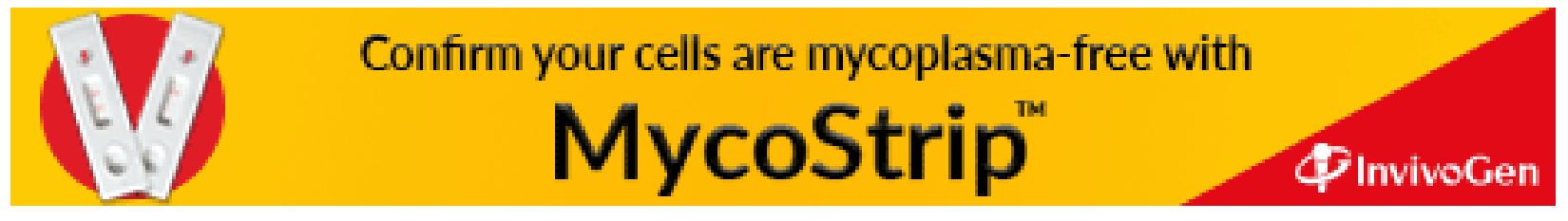

